\title{
SUBSTRATE WETTING UNDER THE CONDITIONS OF DROP FREE FALLING ON A HEATED SURFACE
}

\author{
Ksenia A. Batischeva ${ }^{1}$, Dmitriy V. Feoktistov ${ }^{1,}$, , Sergey Y. Misyura ${ }^{2}$ \\ ${ }^{1}$ National Research Tomsk Polytechnic University, 634050 Tomsk, Russia \\ ${ }^{2}$ S. S. Kutateladze Institute of Thermal Physics, Siberian Branch, Russian Academy of Sciences, 639090 \\ Novosibirsk, Russia
}

\begin{abstract}
We conducted an experimental study of a heated substrate wetting by drops of distilled water under the conditions of their free-falling. The studies were conducted using a shadow system, which consists of a light source, lens and high-speed video camera. It was found that the maximum wetted area of drop is directly proportional to its volume. The main ranges of evolution of distilled water drop behavior on the heated surface (change of geometry at contact with the surface) have been conditionally divided.
\end{abstract}

\section{Introduction}

The operation of thermal engineering equipment in various industries is accompanied by the release of heat [1-7]. Timely heat removal from the equipment of manufacturing line provides required operating mode. Traditionally, the heat exchangers of various types and configurations are used for these purposes. Improving their energy efficiency is possible in the following ways: design of rough surfaces with complex structures [8]; use of special devices for flow turbulization in channels; increase of heat-exchange surface by finning [9]; effect of electric [10], magnetic and ultrasonic fields [11] on the heat transfer agent flow, and others. However, the implementation of such methods of heat transfer intensification requires substantial investment.

Increase in resource and energy efficiency of manufacturing line is possible by implementation of heating equipment with drop [2,6] and film [12-14] surfaces cooling which is capable to remove heat fluxes up to 1000 $\mathrm{W} / \mathrm{cm}^{2}[13]$. The scientific bases for such equipment are not developed at the level for predictive modeling.

The purpose of this work is to define the effect of the initial volume of drop on wetting contact diameter; and to find out the features of the change in a drop geometric shape under the conditions of its free fall on a heated surface.

\section{Experimental method}

Experimental studies were conducted on the setup presented in Fig. 1. The operating principle is given in detail in $[3,4]$. The main elements of experimental setup are light source 1 , condensing lens 5 , test cell consisting of the substrate 4 and transparent box 6 , high-speed video camera 7 .

A round plate made of flexible copper with a diameter of $54 \mathrm{~mm}$ and $4 \mathrm{~mm}$ thick (substrate 4 ) was placed on the electric heating element 3.

a Corresponding author : fdv@tpu.ru 


\section{MATEC Web of Conferences}

Drops with different volumes $(0.006 \mathrm{ml}, 0.012 \mathrm{ml}, 0.018 \mathrm{ml}, 0.023 \mathrm{ml}, 0.048 \mathrm{ml})$ were dosed from a height of $300 \mathrm{~mm}$ on a heated substrate ( substrate temperature was varied from $60^{\circ} \mathrm{C}$ to $200^{\circ} \mathrm{C}$ ).

The wetted area (the main characteristic of spreading) was recorded by the high-speed video camera FastCAMSA1.1 model 675K-M1. Shooting speed of camera is 5000 frames per second at fullscreen scanning $(1280 \times 1024$ resolution, 10 bit $)$.

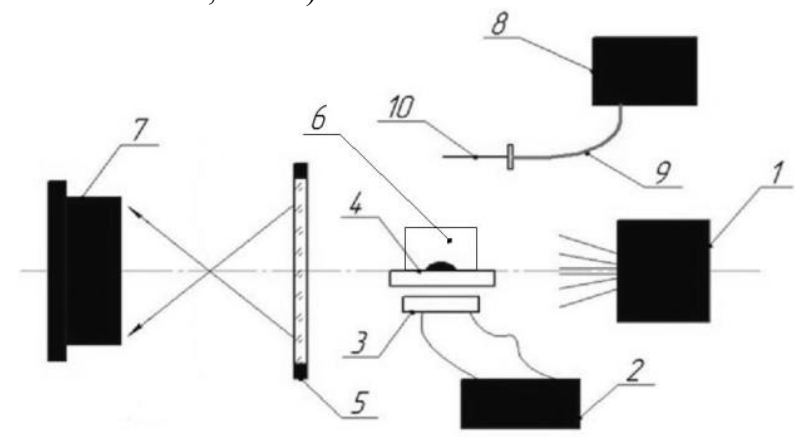

Figure 1. A scheme of experimental setup: 1 - light source, 2 - power unit of heating element, 3 electric heating element, 4 - solid substrate, 5 - condensing lens, 6 - transparent box, 7 - high-speed camera, 8 - electronic unit pump, 9 - pipe for experimental liquid supply, 10 - dosing device.

\section{Experimental results}

The experimental dependences on maximum wetted area of drops with different volumes from the surface temperature are plotted in Fig. 2. According to experimental results directly proportional dependence on maximum wetted area by drops with different volumes from surface temperature has been found.

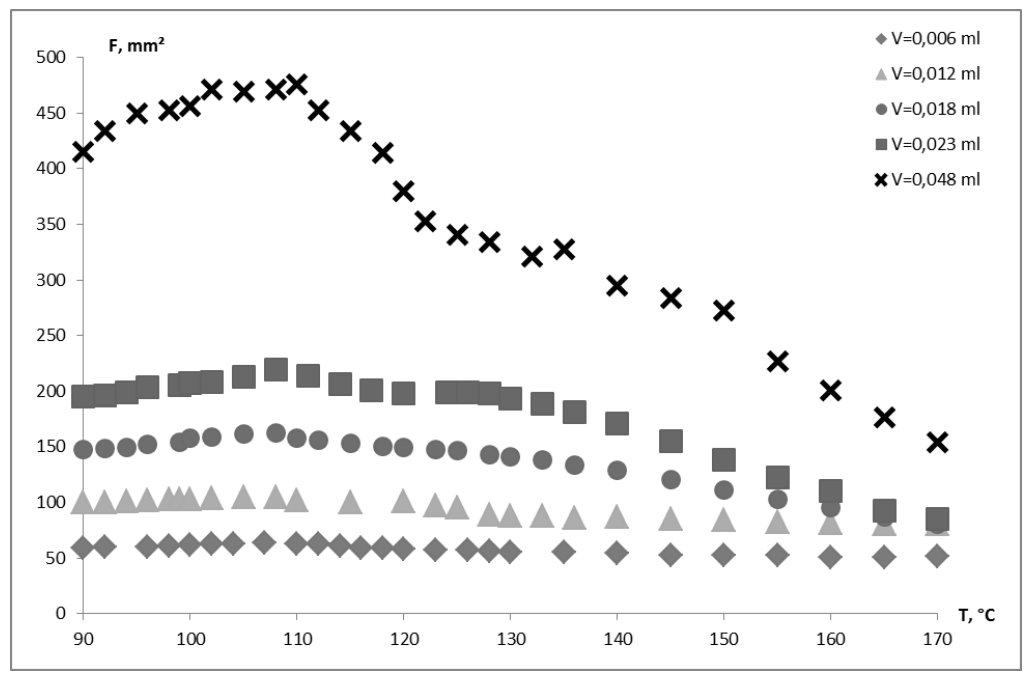

Figure 2. Maximum wetted area of drops versus substrate temperature at different volumes of dosing: 0.006; $0.012 ; 0.018 ; 0.023$ and $0.048 \mathrm{ml}$

The wetted area of drop increases with increasing surface temperature; greatest values are observed for surface temperature of $110^{\circ} \mathrm{C}$. Further increase of the surface temperature leads to decrease of the wetted area. 
Evolution of distilled water drop behavior on the heated surface (change of geometry at contact with the surface) is defined from the analyses of video obtained in the experiment. It can be conventionally divided into five ranges (Table 1) depending on the substrate temperature.

Table 1. Ranges of substrate temperatures

\begin{tabular}{|c|c|c|c|c|}
\hline 1 range & 2 range & 3 range & 4 range & 5 range \\
\hline From 22 & from 100 & from 110 & from 126 & $>135^{\circ} \mathrm{C}$ \\
to $99^{\circ} \mathrm{C}$ & to $109^{\circ} \mathrm{C}$ & to $125^{\circ} \mathrm{C}$ & to $135^{\circ} \mathrm{C}$ & \\
\hline
\end{tabular}

It is known $[1,2,5]$ that the drop spreads or shrinks under the action of inertial force and the attractive force of the molecules.

It is found that for all divided ranges drop spreads to maximum diameter under the inertia forces in the moment of contacting drop and a solid surface. Later, for all ranges, except the fifth, attractive force of molecules contributes droplet shrinking to equilibrium state.

In the fifth range, when the drop reaches the maximum wetting area, it collapses to smaller droplets. Subsequently, physical processes in each temperature range the following:

1. Up to $99^{\circ} \mathrm{C}$ - there is monotonic evaporation with decrease in wetting diameter.

2. From $100^{\circ} \mathrm{C}$ to $109^{\circ} \mathrm{C}$ - vapor bubbles are formed in the created liquid film due to the surface roughness.

3. From $110^{\circ} \mathrm{C}$ to $125^{\circ} \mathrm{C}$ - evaporation process is accompanied by explosive boiling, wherein the liquid is splashed at bubble destruction on the film surface. Contact diameter decreases till forming a hemisphere.

4. From $126^{\circ} \mathrm{C}$ to $135^{\circ} \mathrm{C}$ - evaporation process is accompanied by explosive boiling, contact diameter decreases till forming a hemisphere. Liquid contacts the surface through a vapor cushion, formed as a result of intensive evaporation.

5. More than $135^{\circ} \mathrm{C}$ - explosive boiling with splashing the relatively large liquid particles. Rapid decreasing in the contact diameter, the liquid film breaks up into several parts, which form then spheres contacting the heat surface through a vapor cushion.

It is found that the maximum evaporation rate of liquid is achieved at surface temperature of $125^{\circ} \mathrm{C}$. Further, at increasing the surface temperature of $140{ }^{\circ} \mathrm{C}$ there is a decrease of the liquid evaporation rate. The frequency of contact between the drop and the substrate will be reduced. Thus, the most intensive cooling of the heated surface by drops during their free falling is performed at a surface temperature of $125^{\circ} \mathrm{C}$ and the initial drop volume $\mathrm{V}=0.006 \mathrm{ml}$.

Divided ranges of evolution of distilled water drop behavior on the heated surface correspond to ranges of sessile drop on a heated substrate during "phase transition" [5].

\section{Conclusion}

The following results have been obtained after conducting the experimental investigations of a heated substrate wetting by drops of distilled water under the conditions of their free-falling:

- It was found that the maximum wetted area is directly proportional to the volume of the drop.

- The greatest value of maximum wetted area is observed at the surface temperature of $110^{\circ} \mathrm{C}$.

- Five ranges of evolution of distilled water drop behavior on the heated surface (change of geometry in contact with the surface) are conditionally divided.

- It is found that the maximum evaporation rate of liquid is achieved at surface temperature of $125^{\circ} \mathrm{C}$.

The reported study was supported by RFBR, research project No. 15-38-51075. 


\section{References}

1. E. Ya. Gatapova, A. A. Semenov, D. V. Zaitsev, O. A. Kabov, Colloids Surf., A, 441, 776 (2014).

2. S.Y. Misyura, V.E. Nakoryakov, S.L. Elistratov, Int. J. Heat Mass Transfer, 55 (2012).

3. E.G. Orlova, D.V. Feoktistov, Appl. Mech. Mater., 698 (2015).

4. E.G. Orlova, G. V. Kuznetsov, D. V. Feoktistov, EPJ Web of Conferences 82 (2015).

5. E.V. Anokhina, Tech. Phys., 55, 8 (2010).

6. D.V. Zaitsev, D.P. Kirichenko, O.A. Kabov, Tech. Phys. Lett., 41, 8 (2015).

7. O. Kabov, D. Zaitsev, Dokl. Phys., 7, 1 (2013).

8. H. Song, Y. Lee, S. Jin, H.-Y. Kim, J.Y. Yoo, Microelectron. Eng., 88 (2011).

9. N.I. Pecherkin, A.N. Pavlenko, O.A. Volodin, Int. J. Heat Mass Transfer, 90 (2015).

10. P. Birbarah, Z. Li, A. Pauls, N. Miljkovic, Langmuir, 31, 28 (2015).

11. M.M. Rashidi, M. Nasiri, M. Khezerloo, N. Laraqi, J. Magn. Magn. Mater., 401 (2016).

12. T. Fujita, T. Ueda, Int. J. Heat Mass Transfer, 21, 1 (1978).

13. O.A. Kabov, E.A. Chinnov, Russ. J. Eng. Thermophys., 7, 1 (1997).

14. Y. Kamotani, Prog. Astronaut. Aeronaut., 56 (1977). 